\title{
Penguasaan kemahiran membaca Bahasa Melayu murid bukan penutur jati di Bintulu, Sarawak
}

\author{
The proficiency of Malay Language in reading skills among non-native students \\ at Bintulu, Sarawak
}

\author{
Sylvester Lau Yueh Wei, Alizah Lambri \& Rosliah Kiting \\ Fakulti Bahasa Dan Komunikasi, Universiti Pendidikan Sultan Idris \\ Tanjung Malim, Perak, Malaysia \\ *e-mel: sylvesterlauyuehwei@gmail.com
}

Received: 06 April 2020; Accepted: 26 May 2020; Published: 27 May 2020

To cite this article (APA): Yueh Wei, S. L., Lambri, A., \& Kiting, R. (2020). Penguasaan kemahiran membaca Bahasa Melayu murid bukan penutur jati di Bintulu, Sarawak. EDUCATUM Journal of Social Sciences, 6(1), 3342. https://doi.org/10.37134/ejoss.vol6.1.4.2020

To link to this article: https://doi.org/10.37134/ejoss.vol6.1.4.2020

\begin{abstract}
Abstrak
Kemahiran membaca merupakan kemahiran asas Bahasa Melayu yang perlu dikuasai oleh setiap murid di Malaysia. Kajian ini bertujuan untuk mengenal pasti penguasaan kemahiran membaca Bahasa Melayu murid bukan penutur jati di Bintulu, Sarawak dengan memberikan fokus terhadap asas pembacaan Bahasa Melayu murid bukan penutur jati, tahap kefahaman membaca murid bukan penutur jati terhadap teks naratif dan strategi pengajaran yang dapat membantu murid bukan penutur jati untuk meningkatkan kemahiran membaca dalam mata pelajaran Bahasa Melayu. Responden kajian terdiri daripada 10 orang murid bukan penutur jati di salah sebuah sekolah menengah luar bandar yang terletak di Bintulu, Sarawak. Kajian ini menggunakan pendekatan kualitatif menerusi kaedah kajian kes. Pengutipan data menerusi kajian lapangan dengan menggunakan teknik temu bual dan teknik pemerhatian digunakan untuk proses mengutip data. Dapatan kajian menunjukkan terdapat masalah dalam diri murid bukan penutur jati ini untuk menguasai kemahiran membaca dalam Bahasa Melayu, misalnya salah membunyikan huruf-huruf tertentu, tidak memahami petikan naratif yang diberikan dan tidak mengetahui kepentingan kemahiran membaca Bahasa Melayu. Tujuh daripada sepuluh responden kurang menguasai asas bacaan dengan baik manakala dua daripada sepuluh responden tidak memahami petikan naratif yang diberikan. Selain itu, tiga daripada sepuluh responden menunjukkan mereka tidak pasti tentang kepentingan kemahiran membaca terhadap diri mereka. Pendekatan pengajaran berpusatkan murid merupakan satu kaedah yang dilihat dapat membantu meningkatkan potensi murid-murid bukan penutur jati yang mengalami masalah dalam kemahiran membaca. Implikasi kajian menunjukkan bahawa guru bukan sahaja perlu mengajar murid agar mereka dapat menguasai teknik menjawab soalan peperiksaan dengan baik malah perlu mengajar murid berkaitan dengan kefahaman bacaan supaya mereka dapat memahami teks yang dibaca.
\end{abstract}

Kata kunci: Kemahiran membaca; Bahasa Melayu; penguasaan; murid bukan penutur jati; Bintulu; asas pembacaan; tahap kefahaman; teks naratif; strategi pembelajaran

\begin{abstract}
Reading skills are the basic skills in Malay Language for all school children in Malaysia. The aim of this study is to identify the mastery of Malay Language reading skills among non-native students in Bintulu, Sarawak, with the focus on basic reading skills of Malay Language among non-native students towards narrative texts, and the teaching strategies which can improve the level of reading skills in Malay Language subject. The respondents in this research consist of 10 non-native students at one of the rural school areas in Bintulu, Sarawak. This is a case study which employs a qualitative approach. The data were collected using a field report with techniques of an interview and observation. The research findings showed that there were problems within the non-native students in mastering reading skills in Malay Language, for example, wrong pronunciations of certain words; could not understand the narrative text; and were not aware of the reading skills importance. Seven out of ten respondents
\end{abstract}


could not master the basic reading skills well while two out of the ten respondents could not understand the narrative text given. Besides that, three out of ten respondent were not aware of the importance of reading skills to them. Student-centered learning is perceived as one of the ways to help enhance the potential of non-native students who have problems in reading skills. The implication of this study shows that the teacher should not only teach the students techniques on how to answer exam questions, but they need to teach students reading comprehension so that they can understand what they read.

Keywords: Reading skills; Malay Language; proficiency; non-native students; Malay Language; Bintulu; basic reading skills; level of understanding; narrative text; method to improve reading proficiency

\section{PENGENALAN}

\section{Kemahiran Membaca Bahasa Melayu}

Membaca merupakan sumber ilmu pengetahuan dalam memperolehi sesuatu ilmu pengetahuan yang penting dalam hidup. Tujuan membaca bagi memahami teks yang dibaca dan kandungan teks memberi makna kepada pembaca (Yahya Othman, 2005). Penguasaan kemahiran membaca mendukung makna kebolehan seseorang murid untuk membunyikan sesuatu perkataan, intonasi bacaan, unsur jeda dalam pembacaan dan kelancaran bahasa yang betul. Membaca juga mampu meningkatkan aspek pemahaman dan penaakulan pelbagai bahan bacaan yang merupakan proses dinamik dalam diri seseorang murid (Abdul Rasid Jamian, 2011).

Sejak akhir-akhir ini, kita sering mendengar isu mengenai keciciran murid bukan penutur jati dalam menguasai kemahiran membaca di sekolah. Kita sedia maklum bahawa keupayaan murid untuk menguasai kemahiran membaca amat penting supaya mereka boleh menguasai ilmu dan kemahiran serta nilai murni yang dikehendaki dan termaktub dalam Falsafah Pendidikan Kebangsaan serta Sukatan Pelajaran Bahasa Melayu Sekolah Menengah. Lazimnya, kebanyakan masyarakat peribumi di Sarawak mempunyai pelbagai latar belakang ragam, corak kehidupan, bentuk kebudayaan, adat resam, gaya hidup dan pegangan hidup yang berbeza-beza dan telahpun menjadi amalan sejak zaman-berzaman. Sejajar dengan itu, ini menjadikan penggunaan bahasa Melayu secara langsung tidak dititikberatkan dalam kehidupan seharian mereka. Oleh itu, apabila murid ini berada di sekolah dan mempelajari bahasa Melayu, kemungkinan untuk menguasai bahasa Melayu dengan baik agak tipis lantaran terdapat percanggahan bahasa dengan bahasa ibunda mereka.

Dalam usaha untuk mempertingkatkan penguasaan terhadap mata pelajaran Bahasa Melayu, setiap murid sekolah menengah khususnya murid bukan penutur jati di kawasan Sarawak memerlukan ilmu penguasaan kemahiran membaca yang holistik. Namun begitu, kajian menunjukkan bahawa masih terdapat murid bukan penutur jati yang belum menguasai mata pelajaran Bahasa Melayu secara menyeluruh terutamanya dari aspek sebutan dan intonasi pembacaan bahasa Melayu yang betul. Berikut menunjukkan data literasi Bahasa Melayu dalam kalangan murid Tingkatan 1 di Bintulu Sarawak pada tahun 2017.

Jadual 1: Data tidak menguasai dan menguasai literasi bahasa melayu dalam kalangan murid Tingkatan 1 pada tahun 2017.

\begin{tabular}{|c|c|c|c|c|}
\hline \multicolumn{5}{|c|}{ LITERASI BAHASA MELAYU } \\
\hline DAERAH & $\begin{array}{c}\text { TIDAK } \\
\text { MENGUASAI } \\
\text { (K1-2) }\end{array}$ & $\begin{array}{c}\text { KURANG } \\
\text { MENGUASAI } \\
\text { (K3-12) }\end{array}$ & MENGUASAI & JUMLAH \\
\hline Bintulu & 103 & 368 & 2045 & 2516 \\
\hline
\end{tabular}

(Sumber: Laporan Literasi Bahasa Melayu Sekolah-sekolah Menengah Bintulu, Sarawak; 2017)

Jadual 1.1 menunjukkan bahawa walaupun mereka telah memasuki alam sekolah menengah, tetapi didapati bahawa terdapat sekurang-kurangnya 471 orang murid Tingkatan Satu yang masih lemah dan belum menguasai literasi Bahasa Melayu sepenuhnya. Seperti yang kita sedia maklum, setiap peperiksaan awam di sekolah kebangsaan sama ada sekolah rendah mahupun sekolah menengah di Malaysia mewajibkan agar setiap murid mendapat gred kelulusan dalam mata pelajaran Bahasa Melayu 
bagi melayakkan mereka memperolehi sijil peperiksaan awam. Namun begitu, kebanyakan di sekolah yang majoritinya terdapat ramai bilangan murid bukan penutur jati lazimnya mempunyai permasalahan utama iaitu keupayaan untuk membaca dalam bahasa Melayu. Oleh itu, ini menyebabkan murid bukan penutur jati tidak bersedia untuk mempelajari bahasa Melayu di dalam kelas di samping tidak mempunyai keyakinan untuk berinteraksi dalam bahasa Melayu sesama rakan mereka (Ming, 2015).

\section{Masalah Penguasaan Kemahiran Membaca dalam Kalangan Murid Bukan Penutur Jati}

Menurut Laporan Jabatan Perangkaan Malaysia Negeri Sarawak dalam sektor Jabatan Pendidikan Sarawak pada tahun 2015, kumpulan murid Pribumi Sarawak menunjukkan bilangan statistik melebihi 200000 orang murid di sekolah menengah. Golongan ini terdiri daripada murid bukan penutur jati bahasa Melayu dan merupakan golongan murid yang tergolong dalam kategori Bumiputera. Oleh sebab itu, murid bukan penutur jati ini harus diberikan penekanan dalam sistem pendidikan negara selaras dengan matlamat Pelan Pembangunan Pendidikan Malaysia (2013-2025) yang mengalakkan penyertaan menyeluruh dalam pendidikan peringkat menengah. Seterusnya, masih terdapat permasalahan dalam kalangan murid bukan penutur jati yang tidak menguasai kemahiran membaca bahasa Melayu di Sarawak walaupun kita sedia maklum bahawa membaca merupakan salah satu daripada aspek kemahiran berbahasa yang penting ketika di sekolah. Statistik daripada Laporan Sumber Lembaga Peperiksaan dalam Pelan Pembangunan Pendidikan Malaysia (2013-2025) juga menunjukkan penguasaan mata pelajaran Bahasa Melayu masih gagal dikuasai dalam kalangan murid bukan penutur jati dan ini menyebabkan mereka gagal mencapai gred kelulusan dalam peperiksaan SPM. Keadaan ini berlaku akibat kurangnya penguasaan kemahiran asas berbahasa Melayu secara menyeluruh. Oleh hal yang demikian, pembelajaran bahasa Melayu mestilah diikuti oleh asas pembacaan, tahap kefahaman membaca dan strategi meningkatkan kemahiran membaca dalam diri murid bukan penutur jati ini.

Penguasaan dalam kemahiran membaca penting dalam memastikan murid memahami maklumat dan menghayati teks yang dibaca oleh mereka. Namun begitu, masih terdapat jumlah murid bukan penutur jati yang tidak menguasai aspek penguasaan asas pembacaan bahasa Melayu. Oleh itu, perkara ini mendorong kepada kelemahan dalam menyebut perkataan yang mempunyai ejaan yang tertentu. Murid bukan penutur jati ini juga menjadi tidak yakin, gementar dan gugup ketika mengeja sesuatu perkataan yang mereka tidak pasti akan bunyi sebutannya. Seterusnya, apabila mereka tidak mampu membunyikan perkataan yang dibaca tersebut dengan baik, kebanyakan mereka akan malas untuk mencuba dan membawa kepada konsep kendiri yang rendah. Ini akan menjejaskan keupayaan mereka dalam menguasai kemahiran membaca bahasa Melayu yang lebih berkesan. Oleh hal yang demikian, murid harus didorong untuk menguasai asas bacaan supaya mereka mampu untuk memperolehi lebih banyak maklumat yang tersurat dan tersirat melalui perkataan atau teks yang dibaca. Selain itu, penguasaan dalam asas membaca juga mampu mempengaruhi pencapaian murid dalam mata pelajaran yang lain kerana melalui penguasaan asas membaca tersebut murid dapat memperolehi lebih banyak ilmu pengetahuan daripada pelbagai sumber.

Setiap perkataan mempunyai maklumat eksplisit yang tertentu sama ada melalui simbol-simbol linguistik atau melalui penggunaan tanda baca pada sesuatu bahan bacaan. Menurut Mohd Hafiz bin Mohamad Tarmizi pada tahun 2016, tahap penguasaan membaca murid bukan penutur jati masih berada pada tahap yang rendah meskipun mereka mampu mengenali dan membunyikan perkataan atau sesuatu ayat tersebut. Hal ini mungkin dipengaruhi oleh aspek perbezaan dari segi proses penaakulan literal setiap murid sama ada cepat atau lambat. Selain itu, Abbas Pourhosein Gilakjani pada tahun 2016 membuat satu kajian mengenai cara untuk meningkatkan penguasaan membaca dalam kalangan murid di sekolah. Beliau memberikan penekanan terhadap teknik pembacaan secara efektif. Oleh hal yang demikian, murid bukan penutur jati harus dibimbing untuk mempunyai penguasaan kemahiran membaca khususnya dalam petikan teks naratif yang berkaitan dengan rentetan peristiwa secara berturutan agar murid bukan penutur jati mampu menceritakan semula sesuatu kejadian yang dibaca oleh mereka mengikut aspek yang ingin dikaji iaitu aras pengetahuan, kefahaman, aplikasi, analisis, sintesis dan penilaian.

Apabila seseorang murid tidak menguasai kemahiran membaca bahasa Melayu dengan baik, ini akan menjejaskan proses pembelajaran dan pemudahcaraan $(\mathrm{PdPc})$ di dalam kelas. Ketidakupayaan murid bukan penutur jati ini dalam menguasai kemahiran membaca juga sudah tentu akan memberikan masalah kepada mereka untuk memahami sesuatu kandungan pembelajaran. Akibatnya murid bukan 
penutur jati ini akan terus ketinggalan dalam dunia pendidikan memandangkan bahasa Melayu merupakan bahasa utama yang digunakan oleh guru dalam pengajaran mata pelajaran asas yang lain. Oleh sebab itu, guru memainkan peranan yang sangat penting dalam merangka strategi pengajaran yang berkesan dalam memastikan murid-murid ini mempunyai tahap penguasaan kemahiran membaca yang baik. Guru juga harus mengenal pasti strategi pengajaran yang berkesan dalam meningkatkan penguasaan kemahiran membaca murid bukan penutur di Bintulu, Sarawak. Menurut Khairul (2017), faktor persediaan murid untuk mempelajari dan menerima bahasa Melayu dalam diri murid bukan penutur jati mampu mempengaruhi penguasaan kemahiran membaca mereka. Perkara ini disokong melalui kajian Chew Fong Peng pada tahun 2016 yang menunjukkan bahawa murid-murid bukan penutur jati mempunyai masalah sebutan kerana kurang membaca buku atau bahan bacaan bahasa Melayu. Manakala dalam kajian Indam (2015), beliau menyatakan bahawa aspek persekitaran sekolah, pengurusan sekolah, aspek guru dan pengajaran serta pembelajaran di dalam kelas sebenarnya masih belum cukup kondusif dalam membimbing murid-murid berbangsa Iban dalam meningkatkan penguasaan kemahiran membaca mereka di sekolah pedalaman daerah Kapit, Sarawak. Oleh hal yang demikian, guru perlu memastikan agar murid bukan penutur jati ini mempunyai nilai pembelajaran yang tinggi dalam diri mereka supaya mereka mempunyai usaha, ketekalan dan kejayaan dalam menguasai

kemahiran membaca Bahasa Melayu di samping menanam sikap yang positif misalnya motivasi dalam meningkatkan penguasaan kemahiran membaca bahasa Melayu mereka di sekolah.

Guru boleh memberikan penekanan strategi pengurusan sumber pembelajaran yang merangkumi minat serta motivasi murid bukan penutur jati dalam mempelajari mata pelajaran Bahasa Melayu. Hal ini sedemikian kerana guru harus menitikberatkan aspek tingkah laku dan usaha murid dalam mempengaruhi penerimaan bahasa Melayu dalam diri mereka. Antara subskala strategi ini adalah pengurusan bilik darjah yang membabitkan proses seperti penjadualan, perancangan dan pengurusan masa aktiviti PdPc di dalam kelas. Lazimnya, proses ini bukan sahaja merujuk kepada penyediaan untuk sesi pengajaran di dalam kelas semata-mata tetapi juga kepada penggunaan masa yang berkesan dan penetapan matlamat yang ingin dikecapi oleh guru dalam aspek penguasaan kemahiran membaca bahasa Melayu. Selain itu, guru juga boleh memilih strategi pembelajaran yang sesuai dengan keadaan murid bukan penutur jati di Sarawak. Contohnya, strategi pembelajaran kognitif yang paling asas iaitu strategi rehearsal. Dalam strategi ini, guru meminta murid bukan penutur jati untuk menyebut dan menamakan perkara daripada kandungan pembelajaran yang hendak di ajar. Strategi ini berkesan untuk tugasan yang mudah dengan mengaktifkan maklumat dalam ingatan jangka pendek murid bukan penutur jati ini dalam membuat latih tubi pembacaan. Ini juga secara tidak langsung mampu menarik minat dan daya fokus murid bukan penutur jati dalam menguasai sesuatu pembacaan nilai mata pelajaran tersebut.

\section{OBJEKTIF KAJIAN}

Berdasarkan kajian ini, matlamat penyelidikan yang disasarkan adalah untuk mengenal pasti penguasaan kemahiran membaca Bahasa Melayu murid bukan penutur jati di salah sebuah sekolah di Bintulu, Sarawak. Manakala objektif khusus kajian ini adalah seperti berikut:

1. Mengenal pasti asas pembacaan Bahasa Melayu murid bukan penutur jati sekolah menengah di Bintulu, Sarawak.

2. Mengenal pasti tahap kefahaman membaca murid bukan penutur jati semasa membaca teks naratif Bahasa Melayu.

3. Mengenal pasti strategi pengajaran yang dapat membantu murid bukan penutur jati untuk meningkatkan kemahiran membaca.

\section{SOALAN KAJIAN}

Berdasarkan objektif kajian, maka tiga soalan kajian dibina seperti yang berikut: 
1. Bagaimanakah asas pembacaan Bahasa Melayu murid bukan penutur jati di sekolah menengah di Bintulu, Sarawak?

2. Apakah tahap kefahaman membaca murid bukan penutur jati semasa membaca teks naratif Bahasa Melayu?

3. Apakah strategi pengajaran yang dapat membantu murid bukan penutur jati untuk meningkatkan kemahiran membaca?

\section{METODOLOGI KAJIAN}

Kajian ini merupakan sebuah kajian kualitatif berasaskan kajian kes berbentuk penerokaan iaitu meneroka sejauh mana penguasaan kemahiran membaca bahasa Melayu murid bukan penutur jati di salah sebuah sekolah luar bandar yang terletak di Bintulu, Sarawak. Menurut Merriam (2002), kajian kes boleh digunakan untuk mengumpulkan data kualitatif bagi memahami sesuatu fenomena yang berlaku. Melalui kajian kes ini juga, pengkaji berpeluang untuk meneroka dan memperoleh pemahaman yang lebih mendalam terhadap permasalahan yang ingin dikaji. Seterusnya, jenis kajian kes yang digunakan oleh pengkaji dalam kajian ini adalah satu kes, satu tempat atau 'single case, single site'. Kajian ini terbatas di sebuah sekolah menengah kerana sekolah ini terletak di kawasan luar bandar Bintulu dan persekitaran masyarakat di sekolah ini terdiri daripada $65 \%$ murid bukan penutur jati. Oleh itu, pendekatan kajian kualitatif sememangnya bertepatan dan bersesuaian dengan maklumat yang ingin diperolehi oleh pengkaji dalam kajian ini.

Bagi mendapatkan gambaran yang lebih menyeluruh dalam kajian ini juga, pengkaji menggunakan kaedah kajian lapangan sebagai kaedah kajian. Kaedah kajian merangkumi teknik temu bual, teknik analisis dokumen dan teknik pemerhatian. Ketiga-tiga teknik kajian ini juga akan menjawab segala objektif kajian yang telah dikemukakan. Dalam melaksanakan kajian ini juga, pengkaji telah memilih responden seramai 10 orang murid bukan penutur jati yang terdiri daripada lima buah kelas yang berbeza. Responden terdiri daripada murid tingkatan satu dan berumur dalam lingkungan 12 hingga 13 tahun pada tahun semasa. Responden yang dipilih juga merupakan murid bukan Melayu yang tidak menggunakan bahasa Melayu sebagai medium bahasa utama dalam komunikasi seharian mereka.

Pengumpulan data yang pertama adalah berdasarkan instrumen saringan literasi membaca di mana murid akan diuji dari aspek membunyikan huruf vokal, huruf konsonan, suku kata terbuka, suku kata tertutup, diftong, digraf, konsonan bergabung dan imbuhan. Murid akan ditentukan melalui skor menguasai atau tidak menguasai asas pembacaan. Seterusnya, terdapat petikan naratif yang meminta murid bukan penutur jati untuk membaca petikan tersebut dan kemudiannya menjawab soalan pengkaji berdasarkan aras pembacaan. Pengumpulan data terakhir pula melalui protokol temu bual yang merangkumi strategi pengajaran yang efektif dalam membantu murid bukan penutur jati dalam meningkatkan penguasaan kemahiran membaca mereka.

\section{DAPATAN KAJIAN}

\section{Asas Bacaan Responden}

Hasil dapatan kajian yang telah dijalankan menunjukkan kelemahan murid bukan penutur jati dalam asas bacaan seperti salah membunyikan huruf yang seakan-akan sama bentuknya, membunyikan hurufhuruf tertentu dan keliru membunyikan nama huruf yang seakan-akan sama. Hal ini menyebabkan murid salah faham untuk menyebut susunan rangkai kata, ayat, intonasi dengan gaya yang betul. Murid bukan penutur jati ini juga mengalami kesukaran dalam membaca kata diftong, digraf dan konsonan bergabung dengan sebutan yang lancar dan jelas. Secara keseluruhannya, keputusan asas bacaan menunjukkan seorang responden dari Tingkatan $1 \mathrm{C}$, seorang responden Tingkatan $1 \mathrm{E}$ dan seorang responden Tingkatan 1I masing-masing menguasai asas bacaan dengan baik. Selain itu, dua orang responden dari Tingkatan $1 \mathrm{G}$ dan dua orang responden dari Tingkatan $1 \mathrm{H}$ menunjukkan mereka kurang menguasai asas pembacaan dengan baik manakala bagi kelas 1I, seorang responden kurang menguasai asas pembacaan. Oleh itu, bilangan responden yang boleh membaca dengan baik hanya tiga orang 
responden sahaja manakala tujuh orang responden lagi masih mengalami permasalahan dalam membaca dengan baik sama ada membaca kata diftong, digraf atau konsonan bergabung.

Jadual 2: Keputusan Asas Bacaan Responden

\begin{tabular}{|c|l|c|l|}
\hline Tingkatan & \multicolumn{1}{|c|}{ Kaum } & Jantina & \multicolumn{1}{|c|}{ Keputusan } \\
\hline $1 \mathrm{C}$ & Responden 1: Kayan & Lelaki & Menguasai \\
& Responden 2: Iban & Perempuan & Kurang Menguasai \\
\hline 1E & Responden 3: Iban & Pelaki & Kurang Menguasai \\
& Responden 4: Kayan & Perempuan & Menguasai \\
\hline $1 \mathrm{G}$ & Responden 5: Iban & Lelaki & Kurang Menguasai \\
& Responden 6: Iban & Lelaki & Kurang Menguasai \\
\hline $1 \mathrm{H}$ & Responden 7: Iban & Perempuan & Kurang Menguasai \\
& Responden 8: Iban & Perempuan & Menguasai \\
\hline 1I & Responden 9: Iban & Perempuan & Kurang Menguasai \\
\hline
\end{tabular}

\section{Tahap Kefahaman Pembacaan Teks Naratif Murid Bukan Penutur Jati}

Dapatan kajian berkaitan tahap kefahaman pembacaan murid bukan penutur jati semasa membaca teks naratif menunjukkan kebanyakan responden belum dapat mencapai tahap kemahiran berfikir aras tinggi dan kurang memahami teks naratif yang dibaca. Secara keseluruhannya, bagi kaum Iban, seorang responden langsung tidak memahami petikan yang diberikan, seorang responden berada pada tahap pengetahuan dan lima orang responden berada pada tahap kefahaman dalam aras penguasaan membaca Taksonomi Bloom. Seterusnya, bagi kaum Kayan, kedua-dua responden berada pada tahap kefahaman dalam aras penguasaan membaca Taksonomi Bloom. Bagi kaum lain-lain pula, seorang responden langsung tidak memahami petikan yang diberikan oleh pengkaji.

Jadual 3: Tahap Kefahaman Pembacaan Teks Naratif Murid Bukan Penutur Jati Mengikut Kaum

\begin{tabular}{|l|c|c|c|}
\hline \multicolumn{1}{|c|}{ Tahap Kefahaman } & \multicolumn{2}{c|}{ Kaum } & Lain-lain \\
\cline { 2 - 4 } & Iban & Kayan & 1 \\
\hline Tidak memahami petikan & 1 & & \\
\hline Tahap pengetahuan & 1 & & \\
\hline Tahap kefahaman & 5 & & \\
\hline Tahap aplikasi & & & \\
\hline Tahap analisis & & & 1 \\
\hline Tahap sintesis & & & \\
\hline Tahap penilaian & 7 & & \\
\hline Jumlah Responden $(\mathrm{N})=10$ & & & \\
\hline
\end{tabular}

\section{Strategi Pengajaran yang Dapat Membantu Murid Bukan Penutur Jati untuk Meningkatkan Kemahiran Membaca}

\section{Penerimaan Bahasa Melayu dalam Diri Murid Bukan Penutur Jati}

Data temu bual bersama responden menunjukkan bahawa masih terdapat dalam kalangan murid bukan penutur jati ini yang sememangnya tidak mempunyai minat yang mendalam terhadap pembelajaran Bahasa Melayu di sekolah. Ini secara tidak langsung akan menjejaskan penguasaan kemahiran membaca mereka dalam bahasa Melayu. Selain itu, responden juga menunjukkan bahawa mereka tidak mempunyai nilai motivasi yang tinggi dalam mempelajari mata pelajaran Bahasa Melayu lantaran mereka beranggapan bahawa mata pelajaran lain lebih mengajar mereka sesuatu yang penting dalam kehidupan mereka. 
Saya lebih meminati mata pelajaran lain berbanding mata pelajaran Bahasa Melayu. Hal ini sedemikian kerana mata pelajaran lain mengajar saya banyak benda baru seperti mata pelajaran Geografi. (RI)

Saya lebih meminati mata pelajaran Sains berbanding mata pelajaran Bahasa Melayu. Hal ini disebabkan kerana saya suka melihat tumbuh-tumbuhan dan haiwan. (R2)

Saya lebih meminati mata pelajaran PJK berbanding mata pelajaran Bahasa Melayu kerana saya suka bermain dengan rakan-rakan di padang sekolah. (R3)

Berdasarkan sesi temu bual bersama responden, seorang responden menyatakan bahawa dia lebih berminat untuk mempelajari mata pelajaran yang lain misalnya Geografi berbanding mata pelajaran Bahasa Melayu kerana mata pelajaran Geografi mampu memberikan ilmu pengetahuan yang baru kepada dirinya dan boleh mengajarnya tentang sesuatu yang menarik. Selain itu, responden kedua juga menyatakan bahawa dia lebih meminati mata pelajaran Sains berbanding mata pelajaran Bahasa Melayu kerana dia suka melihat keindahan flora dan fauna dan ingin mempelajarinya dengan lebih mendalam. Seterusnya, responden ketiga pula menyatakan bahawa dia lebih meminati mata pelajaran Pendidikan Jasmani Kesihatan berbanding mata pelajaran Bahasa Melayu kerana dia suka membuat aktiviti yang menyeronokkan bersama rakan-rakan ketika berada di sekolah.

Namun begitu, terdapat juga responden yang mempunyai sikap yang positif dan bermotivasi tinggi untuk mempelajari mata pelajaran Bahasa Melayu lantaran mereka mengetahui kepentingan menguasai kemahiran membaca ini.

Saya meminati mata pelajaran Bahasa Melayu kerana ianya menyeronokkan. Walaupun cikgu jarang membuat aktiviti PdPc di dalam kelas, tetapi kami meminati cara cikgu mengajar. Hal ini disebabkan cikgu tersebut lawak. (R4)

Saya meminati mata pelajaran Bahasa Melayu kerana cikgu baik dan mesra. Cikgu juga sering membawa kertas lembaran kerja atau tugasan untuk diberikan kepada kami. (R5)

Ya, saya suka Bahasa Melayu kerana saya suka belajar tentang bahasa. (R6)

Berdasarkan sesi temu bual di atas, seorang responden menyatakan bahawa dia meminati mata pelajaran Bahasa Melayu kerana guru mata pelajaran yang mengajar mereka mempunyai perwatakan yang menarik dan boleh membuatkan mereka berasa seronok untuk mempelajari mata pelajaran Bahasa Melayu di dalam kelas. Selain itu, responden kelima juga meminati mata pelajaran Bahasa Melayu kerana faktor guru yang baik dan mesra. Akhir sekali, responden keenam mempunyai minat terhadap mata pelajaran Bahasa Melayu kerana minatnya yang mendalam terhadap pembelajaran bidang bahasa. Oleh hal yang demikian, dapatan kajian bagi temu bual ini menunjukkan bahawa guru harus memastikan PdPc yang dijalankan di dalam kelas merangkumi elemen keseronokan dalam pembelajaran dan memastikan mata pelajaran Bahasa Melayu merupakan mata pelajaran yang mudah untuk dikuasai oleh semua murid di samping menekankan penguasaan kemahiran membaca dalam diri mereka.

\section{Strategi Pengajaran}

Data temu bual bersama responden menunjukkan bahawa mereka bersetuju bahawa penguasaan kemahiran membaca amat penting diterapkan melalui sesi PdPc di dalam kelas. Oleh itu, adalah amat penting bagi seseorang guru mencari strategi PdPc pengajaran yang melibatkan bentuk-bentuk strategi berbeza yang digunakan dalam menerima, memproses dan mengeluarkan kembali pelbagai maklumat pembelajaran yang diperolehi, bermula daripada penggunaan strategi asas sehinggalah kepada strategi yang kompleks. Dalam kajian ini, strategi telah dikenal pasti iaitu rehearsal. Strategi rehearsal berkaitan dengan penyebutan dan penamaan sesuatu perkara. Hasil daripada kajian ini juga menunjukkan guru akan meminta mereka untuk melaksanakan aktiviti pembacaan secara langsung di dalam kelas. 
$Y a$, cikgu sering menyuruh kami berdiri di hadapan untuk membaca. Cikgu juga memilih secara rawak murid tersebut. Cikgu meminta untuk membuka buku teks dan membaca petikan yang dikehendaki di hadapan kelas. (R1)

$Y a$, penting. Seterusnya, guru pernah memanggil murid ke hadapan untuk melaksanakan ujian lisan membaca di dalam kelas. Seterusnya, kami dikehendaki untuk membuat ayat berdasarkan perkataan yang dibaca. (R2)

Ya, bagi saya kemahiran dalam bahasa Melayu sangat penting. Saya juga pernah dipanggil oleh cikgu untuk berdiri di hadapan dan seterusnya membaca soalan serta menjawab latihan bahasa Melayu pada papan putih di hadapan kelas, begitu juga dengan rakan-rakan saya yang lain, mereka juga pernah dipanggil cikgu. (R3)

Berdasarkan sesi temu bual bersama responden, seorang responden menyatakan bahawa dia bersetuju akan pentingnya penguasaan kemahiran membaca bahasa Melayu bagi dirinya dan menyatakan bahawa guru pernah memilih secara rawak murid di dalam kelas untuk membaca petikan pada buku teks. Selain itu, responden kedua juga memahami kepentingan penguasaan kemahiran membaca bahasa Melayu dan memberitahu bahawa guru mata pelajaran Bahasa Melayu kelas mereka pernah memanggil rakanrakannya berdiri di hadapan bagi melaksanakan ujian lisan membaca di mana mereka dikehendaki untuk membuat ayat berdasarkan perkataan yang dibaca. Akhir sekali, responden ketiga bersetuju akan kepentingan kemahiran asas bahasa Melayu sangat penting dan menyatakan bahawa dirinya dan rakanrakan sekelas yang lain pernah dipanggil oleh guru untuk berdiri di hadapan kelas untuk membaca soalan serta menjawab latihan yang ditulis pada papan putih oleh guru mereka.

Oleh hal yang demikian, dapatan kajian bagi temu bual ini menunjukkan bahawa guru perlu mencari strategi PdPc pembelajaran kognitif yang melibatkan bentuk-bentuk strategi berbeza yang digunakan dalam menerima, memproses dan mengeluarkan kembali pelbagai maklumat pembelajaran yang diperolehi, bermula daripada penggunaan strategi asas sehinggalah kepada strategi yang kompleks.

\section{PERBINCANGAN}

\section{Asas Pembacaan Murid Bukan Penutur Jati}

Secara puratanya, asas pembacaan murid bukan penutur jati di sekolah kajian masih belum menguasai teknik pembacaan yang betul. Maka, ini menyukarkan mereka untuk menyebut perkataan-perkataan yang mempunyai suku kata lebih daripada tiga suku kata. Selain itu, dapatan kajian juga menunjukkan masih terdapat intonasi bahasa ibunda ketika menyebut perkataan. Malah, terdapat kekeliruan dalam menamakan huruf vokal dan konsonan dengan sebutan yang lancar dan jelas. Dalam kajian Chew Fong Peng (2016), terdapat kesukaran dalam kalangan murid bukan Melayu di sekolah untuk menyebut fonem ' $m$ ', ' $n$ ', 'l', 'd' serta 't'dengan bunyi yang lancar. Menurut pengkaji, cara penyebutan sesuatu perkataan turut dipengaruhi oleh bahasa pertuturan ibunda sesorang murid sejak mereka kecil. Hal ini dibuktikan dengan hasil dapatan pengkaji yang menunjukkan terdapat kekeliruan dalam kalangan responden untuk menamakan huruf vokal dan konsonan dengan sebutan yang lancar dan jelas. Dalam kajian Abdul Rasid Jamian (2011), apabila seseorang murid tidak menguasai kemahiran membaca, ini akan menyebabkan mereka tidak dapat menguasai kemahiran asas bahasa Melayu dengan baik dan seterusnya mengalami kesukaran dalam membunyikan huruf yang seakan-akan sama bentuknya, membunyikan huruf-huruf tertentu dan cenderung untuk menjadi keliru ketika membunyikan nama huruf yang seakan-akan sama. Hal ini seterusnya mendorong salah faham murid untuk menyebut susunan rangkai kata, ayat, intonasi dengan gaya yang betul. Dalam pada itu, didapati responden bukan hanya menggunakan bahasa ibunda mereka ketika berinteraksi dengan ahli keluarga di rumah malah turut menggunakannya untuk bertutur semasa berada di dalam kelas dan juga di persekitaran sekolah seperti kantin. Ini secara tidak langsung mampu menjejaskan kualiti penyebutan bahasa Melayu yang betul dalam kalangan murid bukan penutur jati ini dan akhirnya menjejaskan penguasaan kemahiran membaca bahasa Melayu di sekolah. 


\section{Tahap Kefahaman Membaca Murid Bukan Penutur Jati}

Dapatan kajian menunjukkan aras pembacaan murid bukan penutur jati kebanyakannya berada pada tahap pemahaman teks sahaja. Murid bukan penutur jati ini boleh memberikan sedikit huraian dan makna kepada sesuatu perkara. Namun begitu, mereka sukar untuk menunjukkan contoh lain atau menerangkan idea tersirat dengan ayat tersendiri. Ini bermaksud murid bukan penutur jati ini sukar untuk membuat interpretasi yang mendalam dan sukar untuk menunjukkan bukti kefahaman terhadap teks naratif. Hal ini sedemikian kerana murid bukan penutur jati kurang menguasai kemahiran membaca bahasa Melayu dengan baik. Menurut Abbas Pourhosein Gilakjani (2016), membaca merupakan suatu proses interaksi di mana pembaca akan membina makna yang tersendiri melalui teks yang dibaca dengan menggunakan strategi membaca yang efektif. Murid bukan sahaja berperanan sebagai penerima maklumat, tetapi mereka ini juga berupaya untuk memberikan maklum balas terhadap maklumat yang diterima. Oleh itu, sekiranya murid penutur jati ini mampu menguasai kemahiran membaca bahasa Melayu dengan baik, maka sudah tentu murid bukan penutur jati ini berupaya untuk menilai sesuatu jalan penceritaan berasaskan kriteria yang diingini oleh guru. Lanjutan daripada huraian di atas, proses pengajaran mata pelajaran Bahasa Melayu sebagai bahasa kedua dalam kalangan murid bukan penutur jati di Sarawak sememangnya menjadi suatu cabaran yang besar kepada para pendidik khususnya di kawasan luar bandar. Hal ini sedemikian kerana keadaan persekitaran murid bukan penutur jati tersebut yang kurang menggalakkan terhadap penggunaan bahasa Melayu dalam kehidupan seharian dan kekangan dari segi pendedahan terhadap penggunaan bahasa Melayu. Kajian Ilangko Subramaniam, Noorlafiza Abdul Mauthalib dan Siti Nor Hamahida Zainal (2014) juga menunjukkan di kawasan pedalaman yang penduduknya adalah seratus peratus terdiri daripada masyarakat peribumi Iban dan hidup dalam keadaan tiada kemudahan asas, maka kanak-kanak ini hanya terdedah pada bahasa utama mereka iaitu bahasa Iban sebagai pertuturan seharian. Oleh itu, guru memainkan peranan yang sangat penting dalam memberikan motivasi dan galakan yang positif kepada murid-murid bukan penutur jati agar mereka mampu menguasai kemahiran membaca dengan baik.

\section{Strategi Pengajaran yang Dapat Membantu Murid Bukan Penutur Jati Meningkatkan Kemahiran Membaca}

Dapatan kajian mendapati murid Tingkatan 1 yang bukan penutur jati ini kurang meminati mata pelajaran Bahasa Melayu. Hasil temu bual bersama responden menunjukkan beberapa responden murid tidak berminat untuk mempelajari mata pelajaran Bahasa Melayu kerana mereka beranggapan bahawa mata pelajaran yang lain lebih mengajar mereka sesuatu yang baru. Sebagai contoh, seorang responden menyatakan bahawa dia lebih meminati mata pelajaran lain berbanding mata pelajaran Bahasa Melayu kerana mata pelajaran lain mengajar mereka mengenai banyak ilmu baru yang lebih penting dalam kehidupan mereka. Kajian Tay Meng Guat dan Wong Shia Ho (2016) yang menunjukkan bahawa antara sebab murid bukan penutur jati kelas Peralihan tidak minat terhadap pembelajaran bahasa Melayu kerana mereka tidak faham, mata pelajaran bahasa Melayu dianggap sebagai subjek yang sukar dipelajari, Bahasa Melayu dianggap sebagai subjek yang bosan/ tidak menarik, struktur bahasa Melayu berbeza dengan struktur bahasa lain, penulisan karangan Bahasa Melayu dianggap sukar dan tiada kosa kata yang cukup. Ini secara tidak langsung menjejaskan penguasaan kemahiran membaca murid bukan penutur jati dan tahap penerimaan bahasa Melayu dalam diri mereka. Namun begitu, masih terdapat responden yang mempunyai kesedaran akan kepentingan kemahiran membaca. Antara elemen yang ingin diterokai adalah berkaitan dengan pengetahuan tentang bahasa Melayu sebagai subjek wajib, kemampuan bahasa Melayu dalam meningkatkan pengetahuan dan melalui penguasaan bahasa Melayu dapat meluaskan pandangan (Khairul Nizam, 2017). Oleh itu, guru harus bersikap proaktif dan bijak dalam merancang pembelajaran bahasa Melayu yang berlandaskan ilmu baharu di samping menerapkan penguasaan kemahiran membaca dalam diri murid. Dalam kajian ini juga menunjukkan bahawa strategi pembelajaran kognitif melibatkan strategi berbeza yang digunakan dalam menerima, memproses dan mengeluarkan kembali pelbagai maklumat pembelajaran yang diperolehi bermula daripada penggunaan strategi asas iaitu rehearsal. Strategi ini berkaitan dengan teknik pembelajaran yang mewujudkan hubungan dalaman antara sesuatu perkara yang dipelajari dengan perkara yang telah diketahui, melibatkan strategi seperti ringkasan, prafrasa dan membina analogi dalam memahami hubungan antara idea-idea dan memberikan pemahaman yang mendalam terhadap sesuatu maklumat. Oleh itu, guru 
boleh menggalakkan murid bukan penutur jati ini untuk meningkatkan kemahiran membaca melalui menerima, memproses dan mengeluarkan kembali pelbagai maklumat pembelajaran yang diperolehi di dalam kelas.

\section{KESIMPULAN}

Kelemahan murid bukan penutur jati dalam menguasai kemahiran membaca bahasa Melayu secara tidak langsung akan menjejaskan asas pembacaan dan tahap kefahaman membaca teks dalam mata pelajaran Bahasa Melayu. Selain itu, murid yang lemah dalam penguasaan kemahiran membaca juga akan menyebabkan sikap kurang minat dan motivasi yang rendah dalam mempelajari bahasa Melayu. Hasil dapatan kajian menunjukkan bahawa penguasaan kemahiran membaca masih lemah dalam kalangan murid bukan penutur bukan jati. Lazimnya, penguasaan kemahiran membaca ini bukan sahaja berkaitan kebolehan murid untuk menyebut, mengeja, membatang perkataan dan membaca ayat tetapi sejauh mana tahap kefahaman mereka terhadap sesuatu pembacaan tersebut. Seterusnya, penguasaan kemahiran membaca hanya boleh dikuasai apabila seseorang murid itu mampu memahami bahan bacaan serta boleh mendapat makna daripada bahan bacaan yang dibacanya. Oleh itu, ini menunjukkan bahawa aspek penguasaan kemahiran membaca perlu diberikan penekanan oleh pelbagai pihak dalam membantu murid bukan penutur jati ini untuk menguasai kemahiran asas bahasa Melayu. Dalam pada waktu yang sama, sikap yang positif terhadap bahasa Melayu dan motivasi murid bukan penutur jati dalam mempelajari bahasa Melayu harus dipupuk dari semasa ke semasa agar bahasa Melayu terus dihargai, dipelihara dan berkembang seiring dengan kemajuan negara.

\section{RUJUKAN}

Abbas Pourhosein Gilakjani. (2016). How Can Students Improve Their Reading Comprehension Skill. Journal of Studies in Education, Vol. 6(2), 229-240.

Abdul Rasid Jamian. (2011). Permasalahan Kemahiran Membaca dan Menulis Bahasa Melayu Murid-Murid Sekolah Rendah di Luar Bandar. Jurnal Pendidikan Bahasa Melayu, 1-12.

Chew Fong Peng. (2016). Masalah Pembelajaran Bahasa Melayu dalam Kalangan Murid Cina Sekolah Rendah. Jurnal Pendidikan Bahasa Melayu, 10-22.

Ilangko Subramaniam, Noorulafiza Abdul Muthalib \& Siti Nor Hamahida Zaina (2013). Penggunaan Bahasa Ibunda Dalam Pengajaran Bahasa Melayu Dalam Kalangan Murid Peribumi Di Sekolah Pedalaman Sarawak. Jurnal Pendidikan Bahasa Melayu, Vol 2, m/s 65-74.

Kementerian Pendidikan Malaysia. (2013). Pelan Pembangunan Pendidikan Malaysia 2013-2025. Putrajaya: Kementerian Pendidikan Malaysia.

Khairul Nizam bin Mohamed Zuki. (2017). Penerimaan Bahasa Melayu Sebagai Bahasa Kedua Dalam Kalangan Murid Berbangsa Bajau. International Journal of Humanities and Social Science Invention, 2319-7722.

Merriam, S. B., \& Associates (2002). Qualitative research in practice: Examples for discussion and analysis. San Francisco, CA: Jossey-Bass.

Mohd Hafiz bin Mohamad Tarmizi. (2016). Tahap Kefahaman Membaca antara Murid Pasca LINUS dan Murid Arus Perdana. Tanjung Malim: Universiti Pendidikan Sultan Idris.

Morgan Anak Indam. (2015). Peranan Sekolah Mempengaruhi Kemahiran Membaca Murid-murid Iban Tahap 1 di Sekolah Pedalaman Daerah Kapit, Sarawak. Tanjung Malim: Universiti Pendidikan Sultan Idris.

Rancangan Malaysia Kesebelas 2016-2020. (2015). Kuala Lumpur: Percetakan Nasional Malaysia Berhad.

Sii Kiong Ming. (2014). Tahap Pencapaian Kemahiran Mendengar dan Kemahiran Bertutur dalam Kalangan Pelajar di Sebuah Sekolah Menengah di Bintulu, Sarawak, Master Dissertation. Tanjung Malim: Universiti Pendidikan Sultan Idris.

Tay Meng Guat \& Wong Shia Ho. (2016). Minat Pelajar Bukan Penutur Natif terhadap Pembelajaran Bahasa Melayu. Jurnal Penyelidikan IPGK, 53-63.

Yahya Othman. (2005). Trend dalam pengajaran Bahasa Melayu. Bentong: PTS Publications \& Distributors Sdn.Bhd 